\title{
Importance of the Color Expression of Modern Graphic Design in China
}

\author{
Min Xu \\ Department of Applied Arts, Shanghai Xingjian College, Shanghai, 200027, China
}

Keywords: Graphic design; Chinese color; Application

Abstract: Using traditional art colors, artists and art lovers can draw vivid and beautiful images. With the help of the collocations between colors, they can also combine ideas and feelings with the images to achieve the effect of scene blending. The purpose of this paper is to explore the application of Chinese colors in modern graphic design. It is intended to explore how to combine Chinese traditional aesthetic concepts with modern design more effectively and make China's graphic design further mature.

\section{Introduction}

China is a country with a history of several thousand years of culture. It has continued to flow through the long years of the years, and it has evolved into a multi-ethnic country. All ethnic groups have strong local characteristics and cultural heritage, which have been maintained by the local people before they can be circulated. To a certain extent, art is conceived with the art of color. It is mainly to constantly stimulate internal things and is passed down when it is recognized by people. Nowadays, all kinds of media sprint people's attention. The traditional color of graphic design has not been reduced by half.

\section{The significance of Chinese colors in modern graphic design}

The things that have survived through the history of Langtao are often characterized by their ability to embody spiritual values and certain inner qualities. In the modern people's eyes, with the help of modern color concepts in the inheritance and development of the traditional concept of color, on the one hand to inherit the traditional culture, the other is to inherit the tradition of true meaning.

The traditional form is mainly divided into intangible and tangible. The former refers to the spirit, while the latter reflects the creativity and habit of color. In the development of the era, some of the traditional concepts of color that were originally implicit, will gradually form a tangible tradition. People are more often the inheritance of the inherent possibility of producing this color concept. This state also shows the traditional spirit. status. Chinese philosophical thoughts have gradually merged into modern graphic design, and have formed a harmonious and unified concept with nature. Therefore, only by fully understanding the traditional concept of color and traditional Chinese philosophical thoughts, can designers master the use of color and graphic and other essentials in modern graphic design and design a graphic artwork with Chinese charm[1]. 


\section{Chinese color application in modern graphic design}

Using color in graphic design can vividly show the characteristics of things, such as physical properties. The use of color can express the author's thoughts and feelings as well as the meaning given. It can also bring aesthetic experience to the viewer, and even cause the fluctuation of his heart. The characteristics of color symbolism can perfectly show the intrinsic life of human beings. However, this process requires the use of external environmental colors to achieve the unity of the inner essence and the outer essence.

In Taoist thought, black and white are highly valued, because black is a symbol that is given in the thought, and white is a symbol of nothing. It is precisely because the Taoist thoughts give black and white two different symbolic meanings, which makes the two colors in the traditional art have a role that cannot be ignored. The Buddhist thought is neither as extreme as the Taoist thoughts nor as negative as the Confucian thoughts. It gives the symbolic meaning of white purity. It can be seen that different philosophical thoughts have different understandings of the symbolic meaning of color. Only by understanding the symbolic meanings of various colors and drawing lessons from its essence in Chinese graphic design, can we make the picture full of Chinese colors[2]. The color expression of Chinese paintings is shown in the figure below.

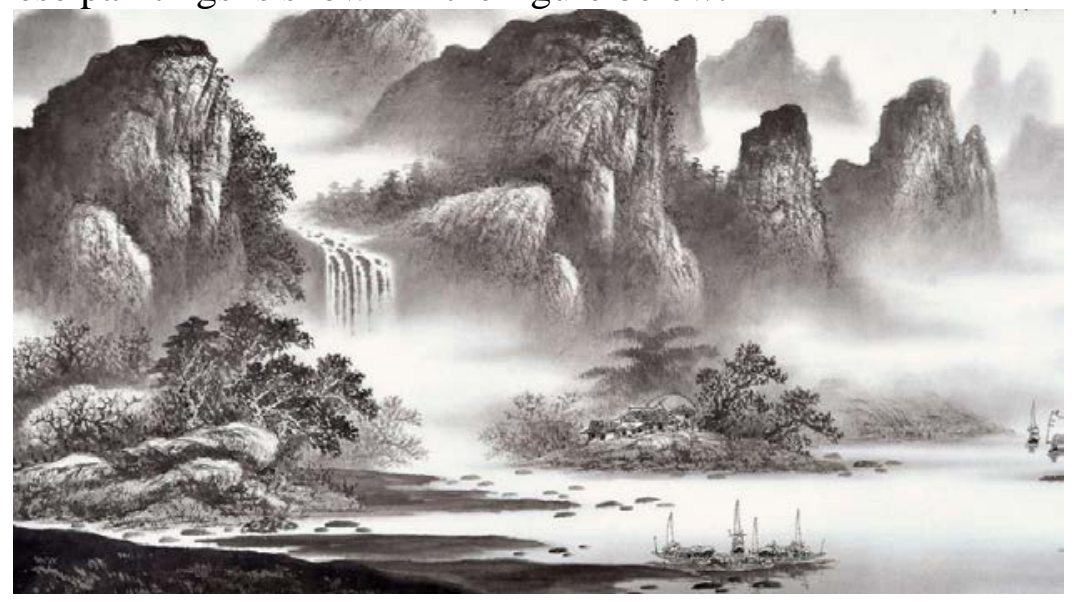

Fig.1 Color expression of Chinese paintings

\subsection{Chinese color decorative applications}

In ancient China, Han Feizi once said that rituals were used by the person with the appearance to decorate the sentence. Its significance is to express the individual's true nature and to restrain its behavior. The decorative nature of Chinese color is the expression of the pursuit of the author's spiritual realm, the reappearance of ancient Chinese philosophy, and also the embodiment of the aesthetic concept that ancient people had in a specific period of time. As time goes by, the decorative features of Chinese colors gradually evolve into a pattern that can be followed. In the works of art, it is possible to perfectly display the decorativeness possessed by Chinese colors through appropriate color relations and formalization.

In the ancient Shang Dynasty in China, the status of solid color in all colors is the highest, and it has developed into a traditional culture. Although color is gradually enriched in the development of society, people's pursuit of pure color has not been weakened. The decorative features of traditional art colors can be more perfect in many aspects, such as having a very high degree of pure color, most of the selected colors are bright and bright colors, and these colors also have a certain relationship, that is, with complementary colors relationship. Under normal circumstances, the complementary color relationship can make the colors form an extra-contrast relationship. Color 
expression conversion formula is as follows.

$$
x_{i j}^{*}=\frac{x_{i j}-\bar{x}_{j}}{s_{j}} \quad i=1,2, \ldots, n ; j=1,2, \ldots, p
$$

Chinese traditional art works require a certain degree of harmony in the matching of colors, so that harmonious colors can be seen in people's eyes. In modern graphic design, various designers with various color relationships are cited in various fashion magazines, packaging, and advertisements. The modern visual missionary effect produced by the graphic design works, the color of his works is often observed by people first, and then is the picture. If a graphic design work uses a high-purity color or a strong contrasting relationship between colors, it will promote the viewer to be seen first among many colors, so as to exchange ideas with the work and form a certain resonance. .Therefore, the combination of modern Chinese graphic design with the color of the decoration can truly reveal the traditional cultural atmosphere for people's visual and spiritual enjoyment [3].

\subsection{The stylized application of Chinese colors}

As Chinese colors continue to be applied by designers, the art color has gradually become a stylized feature. This stylized feature is not only a stylized representation of the symbolic features of color, but also a stylized representation of certain relationships that arise in the process of coordinating and matching colors. In the traditional art works, the harmony and integration between the colors and the works can fully express the meaning of the works. From this we can see that the colors in the works of art are not arbitrarily chosen, and they are arbitrarily matched. It is based on matching color patterns and techniques that have been circulated in the long history.

In China, which is a vast country, people generally believe that red has a good will and a good sign, so red is one of the favorite colors in the dynasties. For example, people are accustomed to tailoring the red double "hi" on wedding occasions to express the meaning of prosperousness. In the course of development, people will use colors such as black, pink, and purple to create a harmonious color image. Red and black in the lacquer ware and New Year paintings of the Han Dynasty have always appeared in people's horizons, gradually forming one of the coordinated color matching methods. The color of the current cross-stitch graphics can reflect people's pursuit of harmonious color matching.

In people's color matching process, especially in modern color science, it may be because the red and green colors have auspicious meanings, and they feel that red and green will give people a fresh feeling. Therefore, These two colors are complementary colors, which is one of the complementary colors. In the ancient people, the people at that time had habitually matched the red with the green, and in the folk also produced a common saying called "to be happy, red and green," the meaning of which was to illustrate the two colors together, Make the collocation effect strong. For example, the main colors used in the forest fire prevention display are mainly green and red. These two colors are more eye-catching and can quickly attract the attention of the audience[4]. The color performance scores are shown in the following table.

Tab.1 Color performance scores

\begin{tabular}{cccccccc}
\hline COLOR & Green & Red & Blue & Yellow & Pink & Black & White \\
\hline RI & 0.00 & 0.00 & 0.58 & 0.90 & 1.12 & 1.24 & 1.32 \\
\hline
\end{tabular}

To sum up, we can clearly see that the symbolic, decorative, and procedural features of Chinese 
colors can be fully tapped in modern graphic design. Color collocations that have been handed down from ancient times are often pursuing harmony and unity. Nowadays, there are more and more ways of color matching. Modern advertisements, trademarks, magazine covers, etc., have different meanings because they have chosen different planes of different colors. Therefore, designers should choose the right color to use in combination with the actual situation and purpose, in order to give full play to the function of color and make readers resonate.

\section{Summary}

With the development of modern society, culture and art are constantly changing. Modern designers not only pursue the modern features and meanings of traditional graphic design when they are engaged in graphic design, but also have international symbols and meanings in combination with graphic design colors. The rational use of China's color in Chinese graphic design and the rational use of Chinese colors in modern graphic design are effective ways to display and promote the national characteristics and artistic qualities of China's fine arts.

\section{References}

[1] Miaoxian Yang,Jiating Li,Chanjuan Ye,Hong Liang. Characterization and expression analysis of a chalcone isomerase-like gene in relation to petal color of Actinidia chrysantha[J]. Biologia,2017,72(7).

[2] Bei Li,Xiao-long He,Yi-ping Zhao,Qi-nan Zhao,Unierhu,Dong-yi Bai,Dugarjaviin Manglai. Tyrosinase-related protein 1 (TYRP1) gene polymorphism and skin differential expression related to coat color in Mongolian horse [J]. Livestock Science, 2014,167.

[3] Vitali M,Conte S,Lessard M,Deschêne K,Benoit-Biancamano M O,Celeste C,Martelli G,Sardi L,Guay F,Faucitano L. Use of the spectrophotometric color method for the determination of the age of skin lesions on the pig carcass and its relationship with gene expression and histological and histochemical parameters.[J]. Journal of animal science, 2017, 95(9).

[4] Vera Cruz Emmanuel M,Brown Christopher L. The influence of social status on the rate of growth, eye color pattern and insulin-like growth factor-I gene expression in Nile tilapia, Oreochromis niloticus.[J]. Hormones and Behavior, 2007, 51(5). 